\title{
20(S)-Ginsenoside Rg3-induced apoptosis in HT-29 colon cancer cells is associated with AMPK signaling pathway
}

\author{
HAI-DAN YUAN ${ }^{1}$, HAI-YAN QUAN ${ }^{1}$, YA ZHANG $^{1}$, SUNG HOON KIM $^{2}$ and SUNG-HYUN CHUNG ${ }^{1}$ \\ ${ }^{1}$ Department of Life and Nanopharmaceutical Science, College of Pharmacy; ${ }^{2}$ Cancer Preventive Material \\ Development Research Center, College of Oriental Medicine, Kyung Hee University, Seoul 130-701, Korea
}

Received February 26, 2010; Accepted June 15, 2010

DOI: $10.3892 / \mathrm{mmr} .2010 .328$

\begin{abstract}
S)-ginsenoside Rg3 [20(S)-Rg3)], one of the main constituents isolated from Panax ginseng, has been shown to have an anti-cancer effect and to induce apoptosis by interfering with several signaling pathways. However, the molecular mechanisms of AMP-activated protein kinase (AMPK) associated with apoptosis in HT-29 colon cancer cells remain unclear. In the present study, we investigated whether 20(S)-Rg3 exerts an anti-proliferative effect and induces apoptosis by modulating the AMPK signaling pathway in HT-29 cells. 20(S)-Rg3-treated cells displayed several apoptotic features, including DNA fragmentation, proteolytic cleavage of poly (ADP-ribose) polymerase (PARP) and morphological changes. 20(S)-Rg3 downregulated the expression of anti-apoptotic protein B-cell CLL/lymphoma $2(\mathrm{Bcl} 2)$, up-regulated the expression of pro-apoptotic protein of p53 and $\mathrm{Bcl}-2$-associated $\mathrm{X}$ protein (Bax), and caused the release of mitochondrial cytochrome $c$, PARP, caspase-9 and caspase-3. However, 20(S)-Rg3induced apoptosis was completely abolished in the presence of compound $\mathrm{C}$ (AMPK inhibitor) or small interfering RNA for AMPK (siAMPK). In addition, STO-609 (CaMKK $\beta$ inhibitor) attenuated 20(S)-Rg3-induced AMPK activation and apoptosis. These results suggest that 20(S)-Rg3-induced apoptosis in HT-29 cells is mediated via the AMPK signaling pathway, and that $20(\mathrm{~S})-\operatorname{Rg} 3$ is capable of inducing apoptosis in colon cancer.
\end{abstract}

\section{Introduction}

Colorectal cancer is one of the leading causes of cancer-related death in Western countries, and its incidence is increasing rapidly in Asia $(1,2)$. Surgical resection followed by adjuvant

Correspondence to: Dr Sung Hyun Chung, Department of Pharmacologcal Science, College of Pharmacy, Kyung Hee University, 1 Hoegi-dong, Dongdaemun-ku, Seoul 130-701, Korea E-mail: suchung@khu.ac.kr

Key words: 20(S)-ginsenoside Rg3, Panax ginseng, apoptosis, AMP-activated protein kinase, HT-29 colon cancer cell chemotherapy has been considered the optimal treatment approach for patients with colon cancer $(3,4)$. However, the approach has a high relapse rate after surgery, and anti-cancer drugs have many detrimental side effects (5). To develop an anti-cancer agent with improved efficacy and minimal toxicity, cancer chemoprevention with medicinal plants has been thoroughly investigated. Numerous reports have documented that anti-cancer components derived from medicinal plants play a partial role in the prevention or therapy of various types of human cancer. These components have been shown to inhibit carcinogenesis by inhibiting cell proliferation and inducing apoptosis $(2,6)$.

Ginseng is a medicinal herb commonly used in Asian countries for numerous purposes $(7,8)$. It has been reported to have anti-proliferative properties in several types of cancer, including ovarian, breast and lung cancer, and melanoma $(9,10)$. Steamed Panax ginseng (red ginseng) is the preferred choice over unsteamed white ginseng (11), as studies have shown that red ginseng has a greater anti-proliferative benefit than white ginseng, most likely due to the differences in their ginsenoside profiles (12). 20(S)-ginsenoside Rg3 (Fig. 1), one of the main constituents found in red ginseng, has been shown to exert inhibitory effects on various cancers through inductive effects on several signaling pathways (13-15). However, it remains to be determined whether apoptotic cell death is associated with the AMP-activated protein kinase (AMPK) signaling pathway in HT-29 colon cancer cells treated with 20(S)-Rg3.

AMPK is a member of a serine/threonine protein kinase and plays an essential role as an energy sensor in eukaryotic cells (16). Recently, AMPK was shown to be involved in cellular homeostasis and emerged as a pivot point between cell survival and apoptosis (16-18). Previous studies have reported that AMPK activation regulates apoptosis in cancer cells via a signaling pathway that includes the up-regulation of p53 protein, activation of caspases, generation of ROS and inhibition of the proteolytic cleavage of poly (ADP-ribose) polymerase (PARP)-LKB1 (17-20).

In the present study, the anti-proliferative activity of 20(S)-Rg3 was determined and its effect was shown to be related to the induction of apoptosis in HT-29 colon cancer cells. The mechanisms of apoptosis induction by $20(\mathrm{~S})-\mathrm{Rg} 3$ were explored with respect to the AMPK signaling pathway. 


\section{Materials and methods}

Reagents. RPMI-1640, FBS and penicillin/streptomycin were obtained from Gibco BRL (Grand Island, NY, USA). Compound $\mathrm{C}$ was from Calbiochem (San Diego, CA, USA) and the Annexin V-FITC apoptosis detection kit was purchased from BD Bioscience (San Diego, CA, USA). Antibodies against phospho-AMPK, AMPK, phospho-ACC, ACC, caspase-3, caspase-9, p53, PARP and CaMKK $\beta$ were from Cell Signaling Technology (Beverly, MA, USA), and Bcl2, Bax, cytochrome $c$ and $\beta$-actin were from Santa Cruz Biotechnology (Santa Cruz, CA, USA). Protein extraction and ECL-reagent kits were from Intron Biotechnology Inc. (Beverly, MA, USA). 20(S)-Rg3 was obtained from the Central Research Center, ILHWA Pharmaceutical Co. (Guri, Korea).

Cell culture and cell survival assay. The HT-29 colon cancer cell line was purchased from the American Type Culture Collection (Rockville, MD, USA), cultured in RPMI-1640 containing $10 \% \mathrm{FBS}, 100 \mathrm{U} / \mathrm{ml}$ penicillin and $100 \mu \mathrm{g} /$ $\mathrm{ml}$ streptomycin, and maintained at $37^{\circ} \mathrm{C}$ in a humidified atmosphere of $5 \% \mathrm{CO}_{2}$ in air. The effects of the $20(\mathrm{~S})-\mathrm{Rg} 3$ on HT-29 cell growth, expressed as the percentage of cell survival, were determined using the MTS assay. The cells were seeded on 96-well plates at $3 \times 10^{4}$ cells/well and treated with various concentrations of $20(\mathrm{~S})-\operatorname{Rg} 3(0,10,50,100$ and $200 \mu \mathrm{M}$ ) for 24 or $48 \mathrm{~h}$. Cell viability was detected by the CellTiter $96^{\circledR}$ AQueous One solution Cell Proliferation Assay (Promega, Madison, WI, USA).

Annexin V-FITC/propidium iodide flow cytometric analysis. Phosphatidylserine on the outside of the apoptoic cells was determined using the Annexin V-FITC apoptosis detection kit. Briefly, HT-29 cells (9x105 cells /well) were treated with various concentrations of $20(\mathrm{~S})-\operatorname{Rg} 3(0,10,50$ and $100 \mu \mathrm{M})$ for $24 \mathrm{~h}$. The cells were collected and resuspended in $100 \mu \mathrm{l}$ of $1 \mathrm{X}$ Annexin binding buffer, then $5 \mu \mathrm{l}$ of conjugated Annexin V-FITC and $10 \mu \mathrm{l}$ of propidium iodide (PI) buffer were added prior to flow cytometric analysis. Cells were excited at $488 \mathrm{~nm}$ and the emission measured at $525 \mathrm{~nm}$ and $610 \mathrm{~nm}$ for Annexin V-FITC and PI fluorescence, respectively. The cells were analyzed using flow cytometry (Beckman, San Diego, CA, USA).

DNA ladder assay. After treatment with $20(\mathrm{~S})-\operatorname{Rg} 3$, the HT-29 cells were lysed in buffer containing $10 \mathrm{mM}$ Tris- $\mathrm{HCl}$, $100 \mathrm{mM} \mathrm{NaCl}, 25 \mathrm{mM}$ EDTA, $0.5 \%$ Triton X-100 and $20 \%$ SDS. Proteinase K $(10 \mathrm{mg} / \mathrm{ml})$ was added and the mixture was incubated for $4 \mathrm{~h}$ at $55^{\circ} \mathrm{C}$, then extracted with phenol:chloroform:isoamyl alcohol (25:24:1). DNA was precipitated with 2 volumes of ice-cold absolute ethanol. After extraction with phenol buffer (phenol-chloroform-isoamyl alcohol), the pellets were incubated with TE buffer $(10 \mathrm{mM}$ Tris-HCl, $1 \mathrm{mM}$ EDTA) and RNase $(2 \mathrm{mg} / \mathrm{ml})$ for $1 \mathrm{~h}$ at $37^{\circ} \mathrm{C}$. DNA fragmentation was determined by electrophoresis on $2 \%$ agarose gel containing ethidium bromide, and photographed using the I-MAX Gel Image analysis system (Core-Bio, Seoul, Korea).

Preparation of whole cell lysates, cytosolic and mitochondrial fractions. For preparation of whole cell lysates, the cells were
$\mathbf{A}$

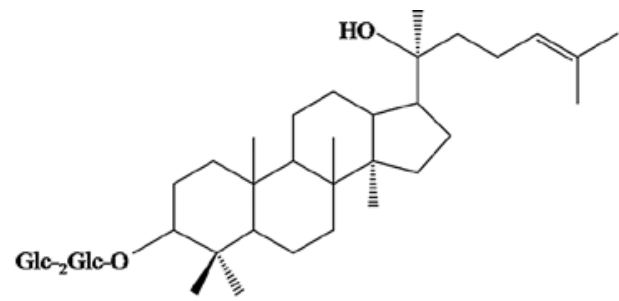

B

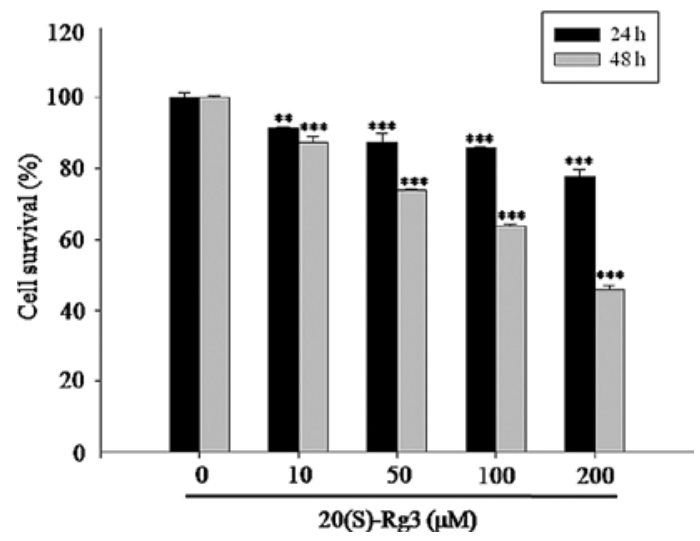

Figure 1. (A) Chemical structure of 20(S)-Rg3. (B) Effect of $20(\mathrm{~S})-\operatorname{Rg} 3$ on the cell viability of HT-29 cells. Data are expressed as the mean \pm SEM of triplicate determinations. ${ }^{* *} \mathrm{p}<0.01$ and ${ }^{* * *} \mathrm{p}<0.001$, significantly different compared to the control, as determined by the Student-Newman-Keul test.

collected, washed twice with ice-cold PBS and lysed using a protein extraction kit. Insoluble protein was removed by centrifugation at $13,000 \mathrm{~g}$ for $15 \mathrm{~min}$. For the preparation of cytosolic and mitochondrial protein, cells were collected and washed twice with ice-cold PBS, then resuspended in ice-cold cell extraction buffer (20 mM HEPES-KOH, $\mathrm{pH} 7.5,10 \mathrm{mM}$ $\mathrm{KCl}, 1.5 \mathrm{mM} \mathrm{MgCl}_{2}, 1 \mathrm{mM}$ EDTA, 1 mM EGTA, $1 \mathrm{mM}$ dithiothreitol, $0.1 \mathrm{mM}$ PMSF, $10 \mu \mathrm{g} / \mathrm{ml}$ pepstatin A and leupeptin) containing $250 \mathrm{mM}$ sucrose for $30 \mathrm{~min}$ on ice. The cells were then homogenized and subjected to centrifugation for $10 \mathrm{~min}$ at $1,000 \mathrm{~g}$ to remove unbroken cells, pellet nuclei and heavy membranes. The postnuclear supernatant was further centrifuged for $30 \mathrm{~min}$ at $13,000 \mathrm{~g}$, and the mitochondria-enriched heavy membrane (pellet) and cytosolic fractions (supernatant) were obtained. The supernatant was collected and stored at $70^{\circ} \mathrm{C}$ for Western blot analysis. The mitochondria rich fraction was solubilized using a protein extraction kit and then centrifuged at $13,000 \mathrm{~g}$ for $15 \mathrm{~min}$. The supernatant was collected and stored at $70^{\circ} \mathrm{C}$ for Western blot analysis.

RNA interference. To knock down endogenous AMPK $\alpha$, HT-29 cells were transiently transfected with $10 \mathrm{nM}$ of chemically synthesized siRNA targeting AMPK $\alpha 1 / 2$ or with non-silencing siRNA using a siRNA transfection reagent according to the manufacturer's recommendations. The transfected cells were used for Western blot analysis.

Immunoprecipitation. Cell lysates (300 $\mu \mathrm{g})$ were pre-cleared with protein $\mathrm{A} / \mathrm{G}$ Sepharose beads and incubated with CaMKK $\beta$ antibody for $4 \mathrm{~h}$ at $4^{\circ} \mathrm{C}$. The reaction mixture was then combined with protein-A/G Sepharose beads and incu- 
A

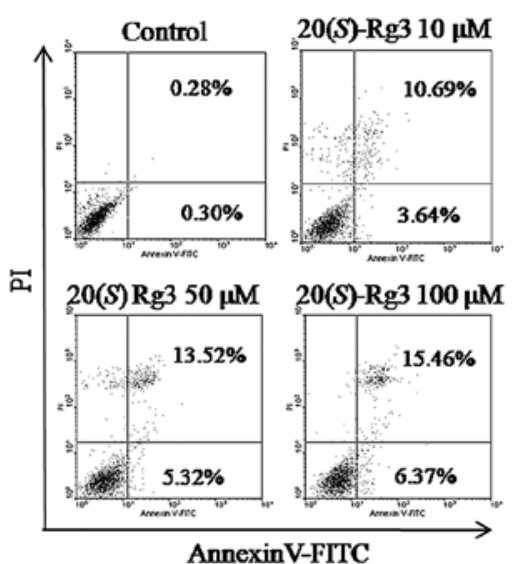

C

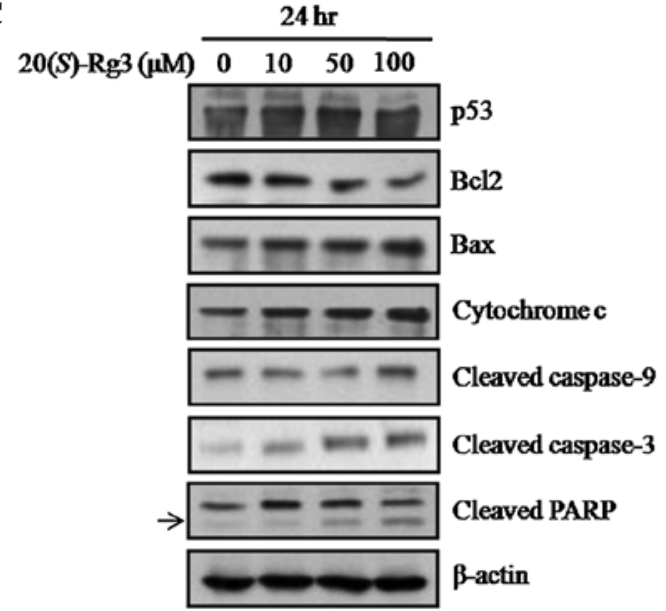

B

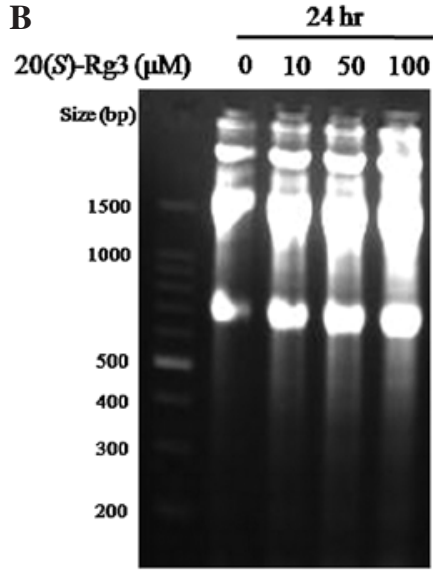

D

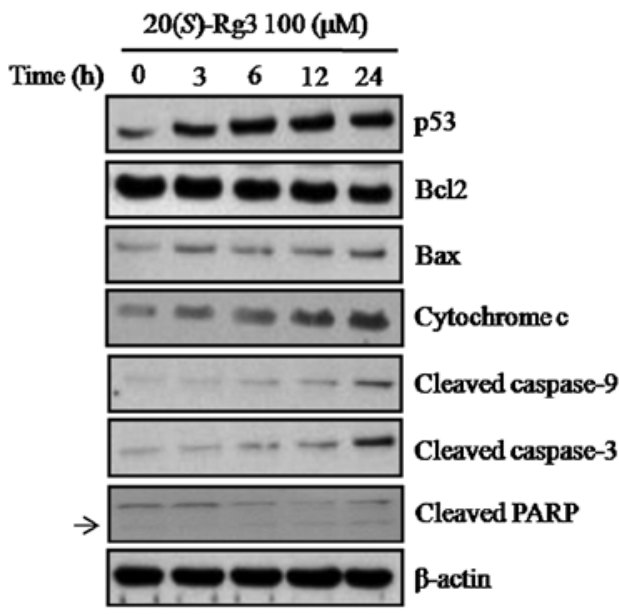

Figure 2. 20(S)-Rg3 induces apoptosis in HT-29 cells. (A) Detection of apoptotic cells by Annexin V and PI double staining. Cells were incubated using the indicated concentrations of 20(S)-Rg3 for $24 \mathrm{~h}$, stained with Annexin V and PI labeling, and analyzed using flow cytometery. (B) DNA fragmentation in HT-29 cells exposed to the indicated concentrations of 20(S)-Rg3 for $24 \mathrm{~h}$. The isolated DNA was loaded into a well on a $2 \%$ agarose gel and electrophoresed Determination of apoptotic proteins in HT-29 cells exposed to the indicated concentrations of $20(\mathrm{~S})-\operatorname{Rg} 3$ for $24 \mathrm{~h}(\mathrm{C})$ or treated with $100 \mu \mathrm{M}$ of $20(\mathrm{~S})-\mathrm{Rg} 3$ for the times indicated (D). Equal amounts of cell lysate ( $40 \mu \mathrm{g}$ of extract) were resolved by SDS-PAGE and analyzed by Western blotting, and the blot was re-probed with anti-actin antibody to confirm equal protein loading.

bated for $2 \mathrm{~h}$ at $4^{\circ} \mathrm{C}$. Following centrifugation at $1,000 \mathrm{~g}$ for $1 \mathrm{~min}$, the precipitate was collected and washed twice with PBS, then 1X SDS buffer was added. After boiling for $1 \mathrm{~min}$, the supernatant was collected. The phosphorylated form of CaMKK $\beta$ was detected using Western blot analysis.

Western blot analysis. Equal amounts of protein $(40 \mu \mathrm{g})$ were resolved by SDS-PAGE and transferred to polyvinylidene difluoride membranes (Millipore, Billerica, MA, USA). The membranes were incubated with appropriate primary antibodies (anti-AMPK, anti-pAMPK, anti-ACC, anti-pACC, anti-p53, anti-Bax, anti-Bcl2, anti-cytochrome $c$, anti-PARP, anti-caspase- 3 and -9 and anti-actin) followed by incubation with horseradish peroxidase-conjugated goat anti-rabbit or donkey anti-rabbit IgG (Santa Cruz Biotechnology) secondary antibodies. Reactive bands were visualized with an enhanced chemiluminescence solution (Amersham, Sweden).

Statistical analysis. Data were presented as the mean \pm SEM. Statistical analysis was performed using one-way ANOVA followed by the Student-Newman-Keuls test. A value of $\mathrm{p}<0.05$ was considered to be significant.

\section{Results}

20(S)-Rg3 inhibited cell proliferation and induced apoptosis. To explore the mechanism by which $20(\mathrm{~S})-\mathrm{Rg} 3$ exerts its effects against colon cancer cells, its effects on cell proliferation were examined first. HT-29 cells $\left(3 \times 10^{4}\right.$ cell/well) were exposed to various concentrations $(0,10,50,100$ and $200 \mu \mathrm{M})$ of 20(S)-Rg3 for 24 h or 48 h. 20(S)-Rg3 showed significant antiproliferative effects in a dose- and time-dependent manner (Fig. 1B). As the colon cancer cells exhibited sensitivity to 20(S)-Rg3 in terms of proliferation, the effect of 20(S)-Rg3 on the level of cellular apoptosis was further examined. HT-29 cells were exposed to various concentrations $(0,10,50$ and $100 \mu \mathrm{M})$ of $20(\mathrm{~S})-\mathrm{Rg} 3$ for $24 \mathrm{~h}$, and the effect of $20(\mathrm{~S})-\mathrm{Rg} 3-$ induced apoptosis was determined using flow cytometry. As shown in Fig. 2A, 20(S)-Rg3 induced apoptosis in a concentration-dependent manner. The percentages of cells in early apoptosis were displayed as 3.64,5.32 and 6.37\% at 10,50 and $100 \mu \mathrm{M}$ of $20(\mathrm{~S})-\mathrm{Rg} 3$, respectively (lower right quadrant). Moreover, late-apoptotic cells were displayed as 10.69, 13.52 and $15.46 \%$ at 10,50 and $100 \mu \mathrm{M}$ of $20(\mathrm{~S})-\mathrm{Rg} 3$ (upper right quadrant). Apoptosis was examined by a DNA ladder assay. 
A

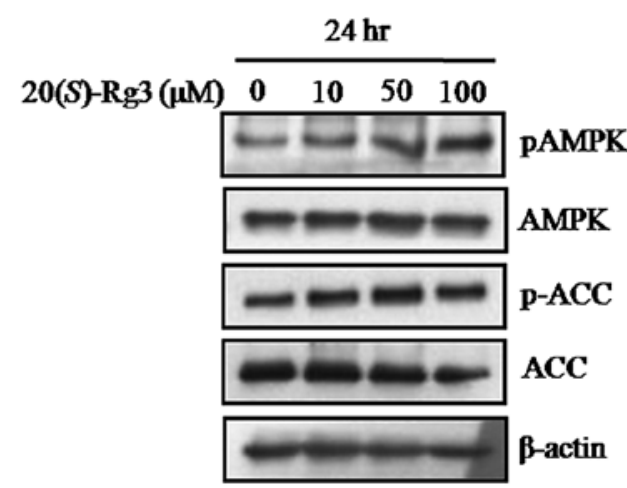

B

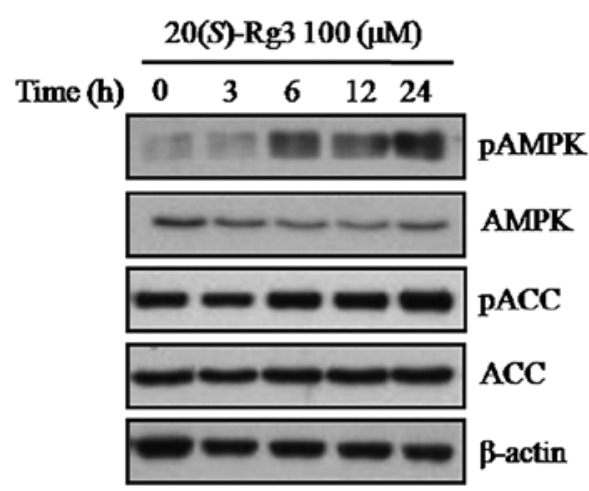

Figure 3. Effect of 20(S)-Rg3 on AMPK and ACC phosphorylation in HT-29 human colon cancer cells. The cells were exposed to the indicated concentrations of 20 (S)-Rg3 for $24 \mathrm{~h}$ (A) or treated with $100 \mu \mathrm{M}$ of $20(\mathrm{~S})-\mathrm{Rg} 3$ for the times indicated (B). Equal amounts of cell lysate (40 $\mu \mathrm{g}$ of extract) were resolved by SDS-PAGE and analyzed by Western blotting, and the blot was re-probed with anti-actin antibody to confirm equal protein loading.

After treating the HT-29 cells with various concentrations of 20(S)-Rg3 for $24 \mathrm{~h}$, typical DNA ladders were clearly visible in Et-Br stained gels (Fig. 2B).

Expression of 20(S)-Rg3-inducedapoptosis-associated proteins. To elucidate the molecular mechanisms of 20(S)-Rg3-induced apoptosis in HT-29 cells, the expression of several apoptosisassociated proteins was examined. HT-29 cells were exposed to various concentrations $(0,10,50$ and $100 \mu \mathrm{M})$ of 20 (S)-Rg3 for $24 \mathrm{~h}$ (Fig. 2C) or treated with $100 \mu \mathrm{M}$ of 20 (S)-Rg3 for up to $24 \mathrm{~h}$ (Fig. 2D). As shown in Fig. $2 \mathrm{C}$ and D, 20(S)-Rg3 induced a decrease in the protein level of $\mathrm{Bcl} 2$ and an increase in the level of Bax in a concentration- and time-dependent manner. A densitometric analysis of the bands revealed that $20(\mathrm{~S})-\mathrm{Rg} 3$ treatment resulted in a dose-dependent increase in the $\mathrm{Bax} / \mathrm{Bcl} 2$ ratio (data not shown). p53 protein expression was increased in a dose- and time-dependent manner. To monitor the release of mitochondrial protein into the cytosol, the cytosolic and mitochondrial fractions were separated and the release of cytochrome $c$ into the cytosol was monitored. As shown in Fig. 2C and D, treatment of HT-29 cells with 20(S)-Rg3 resulted in the release of cytochrome $c$ into the cytoplasm in a concentration- and time-dependent manner. 20(S)-Rg3 treatment was also found to cause a significant increase in the active forms of caspase- 9 and -3 and PARP.

20(S)-Rg3 stimulated AMPK phosphorylation. To investigate the effect of 20(S)-Rg3 on AMPK phorsphorylation, HT-29 cells were exposed to various concentrations $(0,10,50$ and $100 \mu \mathrm{M})$ of $20(\mathrm{~S})-\mathrm{Rg} 3$ for $24 \mathrm{~h}$ or treated with $100 \mu \mathrm{M}$ of 20(S)-Rg3 for up to $24 \mathrm{~h}$. As shown in Fig. 3A and B, 20(S)-Rg3 markedly activated AMPK in a concentrationand time-dependent manner. Consistent with the increase in AMPK activity, the phorsphorylation of ACC, which is an immediate substrate for AMPK, was also increased in a concentration- and time-dependent manner.

20(S)-Rg3 induced apoptosis by activating AMPK. To verify the hypothesis that the apoptosis-inducing activity of 20(S) $-\mathrm{Rg} 3$ is associated with the AMPK pathway, a synthetic AMPK inhibitor (compound C) or small interfering RNA for AMPK were employed. In the presence of compound C
(10 or $20 \mu \mathrm{M}$ ), the 20(S)-Rg3-induced phorsphorylation of AMPK and ACC was significantly attenuated (Fig. 4B). Next, to determine whether AMPK activation by $20(\mathrm{~S})-\mathrm{Rg} 3$ was associated with the induction of apoptosis in HT-29 cells, FACS analysis was performed in order to quantify the rate of cell apoptosis using double staining of Annexin V-FITC and PI. As shown in Fig. 4A, 20(S)-Rg3-induced apoptosis was markedly abrogated by compound C. Next, the expression of apoptotic proteins was determined in the presence of compound C. As shown in Fig. 4C, the 20(S)-Rg3-induced decrease in mitochondrial $\mathrm{Bcl} 2$ protein expression was reversed by pre-treatment with compound C. By contrast, 20(S)- $\mathrm{Rg} 3$-induced increases in $\mathrm{p} 53$, mitochondrial Bax, cytosolic cytochrome $c$ and cleaved caspase- 9 and -3 protein expression were significantly decreased by pre-treatment with compound C. To confirm the effect of compound C on 20(S)Rg3-induced apoptosis, siRNA for AMPK was incubated with cells for $48 \mathrm{~h}$, and then the cells were treated with $20(\mathrm{~S})-\mathrm{Rg} 3$ for $24 \mathrm{~h}$. As shown in Fig. 5A, HT-29 cells transfected with siRNA for AMPK had decreased 20(S)-Rg3-induced AMPK and ACC expression, as compared to the control cells. As expected, siRNA for AMPK reversed 20(S)-Rg3-induced decreases in mitochondrial $\mathrm{Bcl} 2$ protein expression and increases in $\mathrm{p} 53$, mitochondrial Bax, cytosolic cytochrome $c$ and cleaved caspase -9 and -3 protein expression. These results demonstrated that 20(S)-Rg3-induced apoptosis occurred via the AMPK pathway in HT-29 cells.

CaMKK $\beta$ is an upstream kinase for AMPK. In order to further understand the signaling pathway involved in $20(\mathrm{~S})-\operatorname{Rg} 3-$ mediated signaling, HT-29 cells were treated with $100 \mu \mathrm{M}$ of 20 (S) $-\mathrm{Rg} 3$ for up to $24 \mathrm{~h}$, then the protein expression of p-CaMKK $\beta$ was analyzed using Western blot analysis. As shown in Fig. 6A, p-CaMKK $\beta$ protein expression was markedly increased at $24 \mathrm{~h}$ when the cells were treated with $100 \mu \mathrm{M}$ of 20 (S)-Rg3. Next, to determine whether the AMPK activation is caused by CaMKK $\beta$, HT-29 cells were treated with STO-609, a CaMKK $\beta$ inhibitor. Pre-treatment of HT-29 cells with STO-609 significantly attenuated 20(S)-Rg3stimulated phosphorylation of CaMKK $\beta$ in a dose-dependent manner (Fig. 6B), and inhibited the phosphorylation of AMPK and ACC (Fig. 6C). 


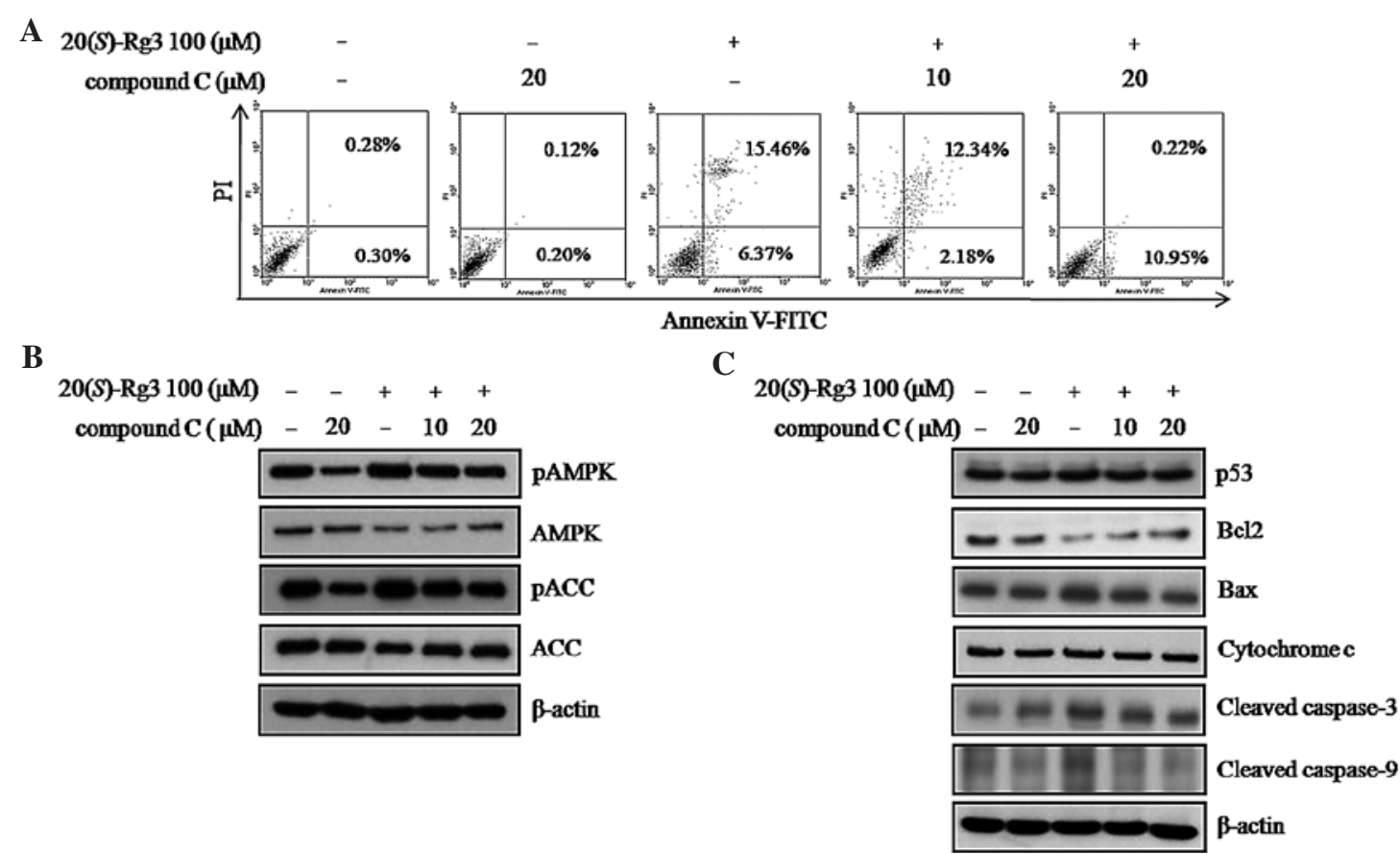

Figure 4. Effects of compound C on (A) 20(S)-Rg3 induced apoptosis, (B) AMPK phosphorylation and (C) expression of apoptosis proteins in HT-29 cells. The cells were pretreated with compound C for $2 \mathrm{~h}$, and treated with 20 (S)-Rg3 for $24 \mathrm{~h}$. Detection of apoptotic cells was performed using Annexin V and PI double staining. The phosphorylation of AMPK and ACC, and the expression of apoptosis-related signal molecules were determined by Western blotting. $\beta$-actin was used as an internal control to evaluate relative protein expression.

A

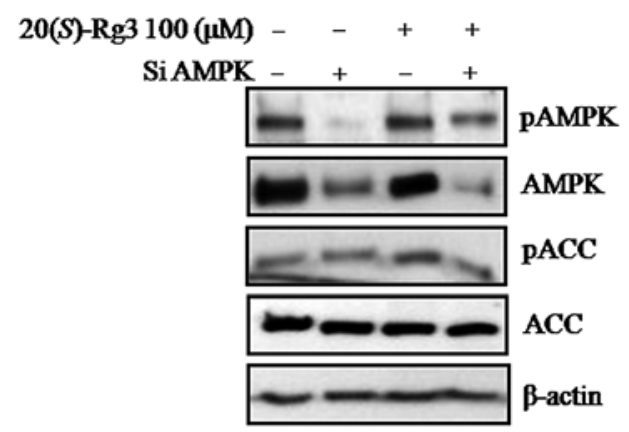

B

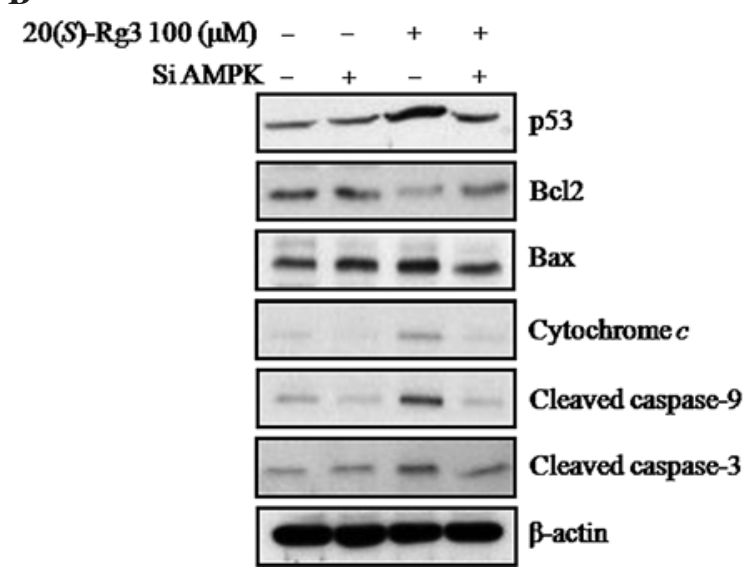

Figure 5. Effects of siRNA for AMPK on (A) 20(S)-Rg3-induced AMPK phorsphorylation and (B) expression of apoptosis-related signal proteins in HT-29 cells. The cells were transfected with AMPK siRNA for $48 \mathrm{~h}$, and exposed to $100 \mu \mathrm{M} 20(\mathrm{~S})-\mathrm{Rg} 3$ for $24 \mathrm{~h}$. Cell lysates were used for Western blot analysis.

A

\begin{tabular}{|c|c|}
\hline \multirow[b]{2}{*}{ Time (h) } & $20(S)-\operatorname{Rg} 3100(\mu \mathrm{M})$ \\
\hline & $\begin{array}{lllll}0 & 3 & 6 & 12 & 2 \\
\end{array}$ \\
\hline
\end{tabular}

B

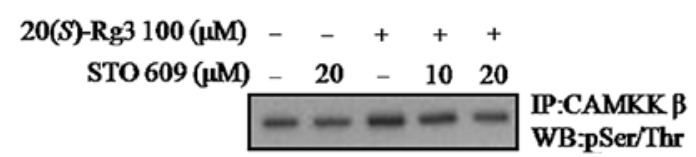

C

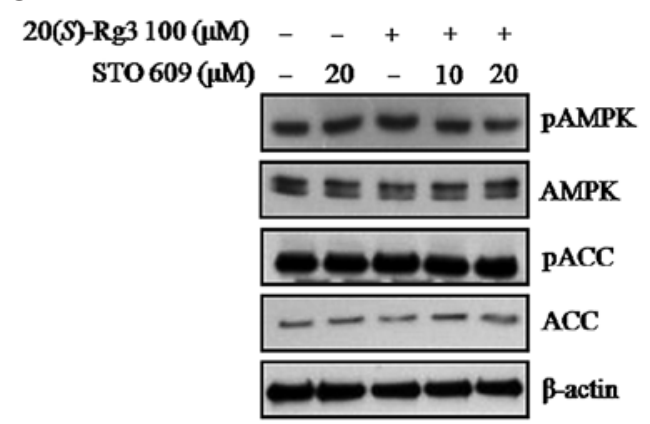

Figure 6. CaMKK $\beta$ is an upstream kinase for 20(S)-Rg3-induced AMPK phorsphorylation in HT-29 cells. The cells were treated with (A) $100 \mu \mathrm{M} 20(\mathrm{~S})-\mathrm{Rg} 3$ for the times indicated and (B) STO-609 for $2 \mathrm{~h}$ prior to stimulation with $100 \mu \mathrm{M} 20$ (S)-Rg3, then immunoprecipitated with an antibody against CaMKK $\beta$ and Thr172. CaMKK $\beta$ and Thr172 phosphorylation was determined by Western blotting. (C) pAMPK and pACC expression in the presence of STO-609 was also determined by Western blotting. 


\section{Discussion}

20(S)-Rg3, one of the main components found in red ginseng, has been shown to inhibit cancer cell proliferation, invasion and metastasis and to induce differentiation and apoptosis $(13-15,21,22)$. As previously reported, the mechanisms responsible for 20(S)-Rg3-induced apoptosis appear to be varied, including NF- $\mathrm{KB}$ and activator protein (AP-1) activation, inhibition of angiogenesis and activation of caspase-3 (13-15). Nevertheless, the cellular and molecular mechanisms underlying 20(S)-Rg3-induced apoptosis associated with AMPK signaling pathway in HT-29 cells have not been defined. The present study demonstrated for the first time that $20(\mathrm{~S})-\mathrm{Rg} 3$ induced the apoptosis of HT-29 cancer cells via the CaMKK $\beta / A M P K$ signaling pathway.

Apoptosis is an important mechanism of 20(S)-Rg3-induced cell death, and susceptibility to the apoptosis of cancer cells is an important determinant of the efficacy of chemotherapy. Our results showed that 20(S)-Rg3 significantly decreased the number of viable cell in a concentration-dependent manner (Fig. 1B). Apoptotic cells induced by 20 (S)-Rg3 displayed DNA fragmentation (Fig. 2B). Annexin-V FITC/PI FACS analysis further confirmed the results of a DNA ladder assay by showing that the membrane alterations related to apoptosis and the percentage of apoptosis were increased in a concentrationdependent manner (Fig. 2B and C). These results suggest that 20(S)-Rg3 markedly inhibited cell proliferation and induced apoptosis in HT-29 colon cancer cells.

Numerous studies have indicated that the apoptotic process in cancer cells occurs via two major pathways. The first pathway operates via death receptors on the cell surface, such as Fas and other members of the tumor necrosis factor (TNF) receptor family, which activates caspase-8. Caspase-8 drives its activation through self-cleavage, and subsequently activates downstream caspases such as caspase-9 and -3 (23). The second pathway involves a mitochondrial pathway that causes the release of cytochrome $c$ into the cytosol, which triggers apoptosis by activation of caspase- 9 in the presence of apoptosis protease activation factor-1 (Apaf-1). This in turn results in the activation of downstream caspase-3, which cleaves PARP $(24,25)$. Recent data indicate that the mitochondrial pathway is controlled and regulated by $\mathrm{Bcl}-2$ family protein (5,22-25). Bcl-2 family proteins such as $\mathrm{Bcl}-2$ and Bax have been identified as major regulators in controlling the release of mitochondrial cytochrome $c$ (26). Moreover, p53-mediated apoptosis is associated with $\mathrm{Bcl}-2$ and $\mathrm{Bax}$ $(27,28)$. Our data indicate that there was an increase in Bax expression and a decrease in $\mathrm{Bcl} 2$ expression, which resulted in a reduction of mitochondrial membrane potential and increased permeability of the mitochondrial outer membrane to cytochrome wc. Released cytochrome $c$ binds to Apaf-1 and activates procaspase-9. Activation of caspase-9 results in the activation of caspase- $3,-6$ and -7 , which function as downstream effectors of the cell death program. Caspase-3 is an executioner caspase activated by either a mitochondrial pathway involving caspase-9 or a death receptor pathway involving caspase-8 (23-25). According to the results shown in Fig. 2C and D, 20(S)-Rg3 induced apoptosis in HT-29 colon cancer cells via the mitochondrial pathway (caspase-9). However, a death receptor pathway cannot be excluded, since procaspase- 8 was also cleaved in a concentration-dependent manner when the cells were treated with $20(\mathrm{~S})-\mathrm{Rg} 3$ (data not shown).

AMPK is a conserved serine/threonine protein kinase regulator of cellular metabolism (29). It has been implicated in various important aspects of cell biology, including the stimulation of angiogenesis, regulation of nitric oxide synthesis and apoptosis (30-33). In the present study, we examined whether 20(S)-Rg3-induced apoptosis is associated with AMPK activation. Our results show that 20(S)-Rg3 stimulated AMPK activation in HT-29 colon cancer cells (Fig. 3A and B), and that 20(S)-Rg3-induced apoptosis was completely inhibited by both AMPK inhibitor (compound C) or siAMPK (Figs. 4 and 5). These results suggest that 20(S)-Rg3-induced AMPK activation may be responsible for 20(S)-Rg3-induced apoptosis, and that it serves as a positive regulator of apoptosis. Currently, LKB 1 and CaMKK are the known upstream kinases of AMPK (34). To identify upstream kinases for AMPK, we examined whether 20(S)-Rg3 is capable of activating LKB1 and CaMKK in HT-29 cells. As shown in Fig. 6, 20(S)-Rg3 phosphorylated CaMKK $\beta$ in a time-dependent manner, and 20(S)-Rg3-induced phosphorylation of CaMKK $\beta$ and AMPK was inhibited in the presence of a CaMKK inhibitor, STO-609. Of note, LKB1 was also activated by $100 \mu \mathrm{M}$ of 20 (S)-Rg3 in a time-dependent fashion (data not shown). Therefore, LKB1 and CaMKK both were considered as upstream kinases for AMPK in 20(S)-Rg3-induced apoptotic event of HT-29 cells.

In conclusion, we examined the pathway involved in 20(S)Rg3-induced apotosis in HT-29 colon cancer cells, and found that 20(S)-Rg3-induced apoptosis mainly requires the mitochondrial pathway involving Bax/cytochrome $c /$ caspase-9, and that this apoptosis occurred via the activation of the AMPK pathway. These findings suggest that the AMPK signaling pathway is associated with apoptosis induction by $20(\mathrm{~S})-\mathrm{Rg} 3$ in HT-29 colon cancer cells, and is worth exploring as a potential target for colon cancer.

\section{Acknowledgements}

This work was supported by the Korea Science and Engineering Foundation (KOSEF) grant funded by the Korean government (MEST) (No. R13-2009-019-00000-0).

\section{References}

1. Wang JB, Qi LL, Zheng SD and Wu TX: Curcumin induces apoptosis through the mitochondria-mediated apoptotic pathway in HT-29 cells. J Zhejiang Univ Sci B 10: 93-102, 2009.

2. Lee JH, Yang HS, Park KW, Kim JY, Lee MK, Jeong IY, Shim KH, Kim YS, Yamada K and Seo KI: Mechanisms of thiosulfinates from Allium tuberosum L.-induced apoptosis in HT-29 human colon cancer cells. Toxicol Lett 188: 142-147, 2009.

3. Kosmider S and Lipton L: Adjuvant therapies for colorectal cancer. World J Gastroenterol 13: 3799-3805, 2007.

4. Monga DK and O'Connell MJ: Surgical adjuvant therapy for colorectal cancer: current approaches and future directions. Ann Surg Oncol 13: 1021-1034, 2006.

5. Li WJ, Nie SP, Yu Q and Xie MY: (-)-Epigallocatechin-3-gallate induces apoptosis of human hepatoma cells by mitochondrial pathways related to reactive oxygen species. J Agric Food Chem 57: 6685-6691, 2009. 
6. Yoshimoto M, Yahara S, Okuno S, Islam MS, Ishiguro K and Yamakawa O: Antimutagenicity of mono-,di-, and tricaffeoylquinic acid derivatives isolated from sweetpotato (Ipomoea batatas $L$.) leaf. Biosci Biotechnol Biochem 66: 2336-2341, 2002.

7. Ang-Lee MK, Moss J and Yuan CY: Herbal medicines and perioperative care. JAMA 286: 208-216, 2001.

8. Yun SN, Ko SK, Lee KH and Chung SH: Vinegar-processed ginseng radix improves metabolic syndrome induced by a high fat diet in ICR mice. Arch Pharm Res 30: 587-595, 2007.

9. Wang W, Zhao Y, Rayburn ER, Hill DL, Wang H and Zhang R: In vitro anti-cancer activity and structure-activity relationships of natural products isolated from fruits of Panax ginseng. Cancer Chemother Pharmacol 59: 589-601, 2006.

10. Koo HN, Jeong HJ, Choi IY, An HJ, Moon PD, Kim SJ, Jee SY, Um JY, Hong SH, Shin SS, Yang DC, Seo YS and Kim HM: Mountain-grown ginseng induces apoptosis in HL-60 cells and its mechanism have little relation with TNF-alpha production. Am J Chin Med 35: 169-182, 2007.

11. Kim WY, Kim JM, Han SB, Lee SK, Kim ND, Park MK, Kim CK and Park JH: Steaming of ginseng at high temperature enhances biological activity. J Nat Prod 63: 1702-1704, 2006.

12. Wang CZ, Aung HH, Ni M, Wu JA, Tong R, Wicks S, He TC and Yuan CS: Red American ginseng: ginsenoside constituents and antiproliferative activities of heat-processed Panax quinquefolius roots. Planta Med 73: 669-674, 2007.

13. Keum YS, Han SS, Chun KS, Park KK, Park JH, Lee SK and Surh YJ: Inhibitory effects of the ginsenoside Rg3 on phorbol ester-induced cyclooxygenase-2 expression, NF-kappaB activation and tumor promotion. Mutat Res 523: 75-85, 2003

14. Iishi H, Tatsuta M, Baba M, Uehara H, Nakaizumi A, Shinkai K, Akedo H, Funai H, Ishiguro S and Kitagawa I: Inhibition by ginsenoside $\operatorname{Rg} 3$ of bombesin-enhanced peritoneal metastasis of intestinal adenocarcinomas induced by azoxymethane in Wistar rats. Clin Exp Metastasis 15: 603-611, 1997.

15. Lee SY, Kim GT, Roh SH, Song JS, Kim HJ, Hong SS, Kwon SW and Park JH: Proteomic analysis of the anti-cancer effect of 20S-ginsenoside Rg3 in human colon cancer cell lines. Biosci Biotechnol Biochem 73: 811-816, 2009.

16. Lee YK, Park SY, Kim YM, Lee WS and Park OJ: AMP kinase/ cyclooxygenase-2 pathway regulates proliferation and apoptosis of cancer cells treated with quercetin. Exp Mol Med 41: 201-207, 2009.

17. Huang CH, Tsai SJ, Wang YJ, Pan MH, Kao JY and Way TD EGCG inhibits protein synthesis, lipogenesis, and cell cycle progression through activation of AMPK in p53 positive and negative human hepatoma cells. Mol Nutr Food Res 53: 1156-1165, 2009.

18. Hardie DG: New roles for the LKB1 $\rightarrow$ AMPK pathway. Curr Opin Cell Biol 17: 167-173, 2005.

19. Su RY, Chao Y, Chen TY, Huang DY and Lin WW: 5-Aminoimidazole-4-carboxamide riboside sensitizes TRAILand TNF\{alpha\}-induced cytotoxicity in colon cancer cells through AMP-activated protein kinase signaling. Mol Cancer Ther 6: 1562-1571, 2007.

20. Shin SM, Cho IJ and Kim SG: Resveratrol protects mitochondria against oxidative stress through AMPK-mediated GSK3 3 beta\} inhibition downstream of poly (ADP-ribose) polymerase-LKB1 pathway. Mol Pharmacol 76: 884-895, 2009.
21. Sai K, Yang D, Yamamoto H, Fujikawa H, Yamamoto S, Nagata T, Saito M, Yamamura T and Nishizaki T: A(1) adenosine receptor signal and AMPK involving caspase-9/-3 activation are responsible for adenosine-induced RCR-1 astrocytoma cell death. Neurotoxicology 27: 458-467, 2006.

22. Mochizuki M, Yoo YC, Matsuzawa K, Sato K, Saiki I, Tono-oka S, Samukawa K and Azuma I: Inhibitory effect of tumor metastasis in mice by saponins, ginsenoside-Rb2, 20(R)and 20(S)-ginsenoside-Rg3, of red ginseng. Biol Pharm Bull 18: 1197-1202, 1995.

23. Shinkai K, Akedo H, Mukai M, Imamura F, Isoai A, Kobayashi M and Kitagawa I: Inhibition of in vitro tumor cell invasion by ginsenoside Rg3. Jpn J Cancer Res 87: 357-362, 1996.

24. Chio JH, Lee HW, Park HJ, Kim SH and Lee KT: Kalopanaxsaponin A induces apoptosis in human leukemia U937 cells through extracellular $\mathrm{Ca}^{2+}$ influx and caspase- 8 dependent pathways. Food Chem Toxicol 46: 3486-3492, 2008.

25. Kim SS, Won SJ, Kim NJ, Yoo JK, Bae K and Lee KT: 3-Oxoolean-12-en-27-oic acid isolated from Aceriphyllum rossii induces caspase-8-dependent apoptosis in human promyelocytic leukemia HL-60 cells. Biol Pharm Bull 32: 91-98, 2009.

26. Yan Y, Su X, Liang Y, Zhang J, Shi C, Lu Y, GU L and Fu L: Emodin azide methyl anthraquinone derivative triggers mitochondrial-dependent cell apoptosis involving in caspase-8mediated Bid cleavage. Mol Cancer Ther 7: 1688-1697, 2008.

27. Mancini F, Di Conza G, Pellegrino M, et al: MDM4 (MDMX) localizes at the mitochondria and facilitates the p53-mediated intrinsic-apoptotic pathway. EMBO J 28: 1926-1939, 2009.

28. Bourgarel-Rey V, Savry A, Hua G, Carré M, Bressin C, Chacon C, Imbert J, Braguer D and Barra Y: Transcriptional down-regulation of $\mathrm{Bcl}-2$ by vinorelbine: identification of a novel binding site of $\mathrm{p} 53$ on $\mathrm{Bcl}-2$ promoter. Biochem Pharmacol 78: 1148-1156, 2009.

29. Hay N: The Akt-mTOR tango and its relevance to cancer. Cancer Cell 8: 179-183, 2005.

30. Webler AC, Michaelis UR, Popp R, Barbosa-Sicard E, Murugan A, Falck JR, Fisslthaler $B$ and Fleming I: Epoxyeicosatrienoic acids are part of the VEGF-activated signaling cascade leading to angiogenesis. Am J Physiol Cell Physiol 295: C1292-C1301, 2008.

31. Youn JY, Wang T and Cai H: An ezrin/calpain/PI3K/AMPK/ eNOSs1179 signaling cascade mediating VEGF-dependent endothelial nitric oxide production. Circ Res 104: 50-59, 2009.

32. Hwang JT, Ha J, Park IJ, Lee SK, Baik HW, Kim YM and Park OJ: Apoptotic effect of EGCG in HT-29 colon cancer cells via AMPK signal pathway. Cancer Lett 247: 115-121, 2007.

33. Hurley RL, Anderson KA, Franzone JM, Kemp BE, Means AR and Witters LA: The $\mathrm{Ca}^{2+} /$ calmodulin-dependent protein kinase kinases are AMP-activated protein kinase kinases. J Biol Chem 280: 29060-29066, 2005

34. Lage R, Diéguez C, Vidal-Puig A and López M: AMPK: a metabolic gauge regulating whole-body energy homeostasis. Trends Mol Med 14: 539-549, 2008. 